\title{
RETROGRADE AMNESIA AND REMOTE MEMORY IMPAIRMENT
}

\author{
NeAl J. COHEN* \\ Department of Neurosciences, University of California School of Medicine, La Jolla, California, U.S.A. \\ and \\ LARRY R. SQUIRE $\dagger$ \\ Veterans Administration Medical Center, San Diego, California and the Department of Psychiatry, University \\ of California School of Medicine, La Jolla, California, U.S.A.
}

(Received 3 November 1980)

\begin{abstract}
The status of remote memory in case N.A., patients receiving bilateral ECT, and patients with Korsakoff syndrome was assessed using seven different tests. The extent and pattern of remote memory impairment depended upon the etiology of ammesia, appearing as a relatively brief retrograde amnesia for N.A. and patients receiving ECT and as an extensive impairment covering many decades for patients with Korsakoff syndrome. Differences in remote memory impairment could not be explained by differences in the severity of anterograde amnesia, indicating that amnesia is not a unitary disorder. We suggest that brief retrograde amnesia is typically present whenever amnesia occurs and that extensive remote memory impairment is a distinct entity related to superimposed cognitive deficits. These ideas and a review of previous studies lead to a comprehensive proposal for understanding retrograde amnesia and remote memory impairment.
\end{abstract}

THE AMNESIC syndrome has been the subject of much interest in neuropsychology because of what it might reveal about the organization and neurological foundations of normal memory. The phenomenon of retrograde amnesia, that loss of memory can occur for the period before the precipitating incident, has had a particularly large impact on ideas about normal memory function [1-5]. However, conflicting views exist regarding both the extent and pattern of retrograde amnesia and these have been used to support different ideas about the nature of amnesia.

Specifically, clinical assessment of memory loss in patients with medial temporal lobectomy has suggested that a relatively brief retrograde amnesia extends at least to several months and at most to a few years prior to surgery $[6,7]$. Formal testing of patients receiving bilateral electroconvulsive therapy (ECT) has revealed a brief retrograde amnesia affecting memory for public events and former television programs that occurred during the few years prior to treatment [8-10]. These findings, together with studies of anterograde amnesia, are consistent with theories of amnesia that emphasize deficiency in the storage or consolidation of new information $[1,11,12]$. By contrast, formal testing of patients with Korsakoff syndrome has revealed an extensive impairment of remote memory for public events [13-15], famous faces $[2,13,15]$, and famous voices [16] that covers several decades. These

\footnotetext{
* Now at Department of Psychology, Massachusetts Institute of Technology, Cambridge, MA 02139.

†Correspondence to Larry R. Squire, Veterans Administration Medical Center, 3350 La Jolla Village Drive, V-116A, San Diego, CA 92161, U.S.A.
} 
results support suggestions that amnesia involves a general defect in memory retrieval $[3,17]$.

Interpretation of these different results has been complicated by the fact that they reflect different amnesic groups given different tests by different investigators. The present study reports our assessment of remote memory capacity using seven different tests for each of three etiologically-distinct amnesias: case N.A., patients receiving bilateral ECT, and patients with Korsak off syndrome. Some of the results with case N.A. and patients receiving ECT have been reported previously, as described below, and they are included here to facilitate comparisons between groups. In addition, we have assessed the severity of anterograde amnesia in these three groups.

\section{METHOD}

Subjects

Case N.A. This patient has been severely amnesic for verbal material since 1960 , when at the age of 22 years he sustained a stab wound to the brain with a miniature fencing foil $[12,18]$. Recent CAT scans have identified a lesion in the left dorsal thalamus of this patient in a position corresponding to the dorsomedial nucleus [19]. His memory deficit occurs despite above average intelligence (W.A.I.S. $=124$ [12]), and without any known defects in language or visuoperceptual ability.

Patients receiving bilateral electroconvulsive therapy $(E C T)$. The present group consisted of 12 females and 6 males ( mean age $=47.1$ years; mean education $=12.2$ years) prescribed FCT for relief of depressive illness. Three patients had received a previous course of treatment, and none had received ECT within the previous two years. Each patient was tested on the day prior to the first treatment of their series, and again at least one hour after the fifth treatment, when amnesia is present as a relatively circumscribed disorder (Table 1 , and $[20,21]$ ).

Patients with alcoholic Korsakoff syndrome. Nine alcoholic patients with Korsakoff syndrome residing in San Diego County participated in these studies. This group of six men and three women averaged 53.8 years of age, with an average of 13.0 years of education. Their average full-scale IQ was 101.1 and their average Wechsler Memory Scale score was 76.2. Neuropsychological screening and independent neurological evaluation indicated that memory impairment was the only remarkable defect of higher cortical function. All of these patients could draw a cube and a house in perspective, and none had aphasia or apraxia.

Control groups for case N.A. A total of 28 male V.A. hospital employees served as control subjects for the experiments in the present report. This subject pool was matched to N.A. for age ( $\vec{x}=38.9$ years vs. 41 years for N.A.), education $(\bar{x}=14.6$ years vs. 13 years for N.A.), and WAIS subtest scores (general information: $\bar{x}=22.9$ vs. 22 for N.A.; vocabulary $\bar{x}=61.6$ vs. 66 for N.A.).

Control groups for patients with Korsakoff syndrome. Two control groups were used for the patients with Korsak off syndrome. The first group consisted of 28 male alcoholics, enrolled in an alcohol treatment program, who had been free of alcohol for a minimum of two weeks $(\bar{x}=$ five weeks). Their average drinking history was 25 years, without history of head injury or liver disease. The alcoholics averaged 51.1 years of age (Korsakoff patients $=53.8$ years), had 11.4 years of education (Korsakoff patients $=13.0$ years), and had WAIS subtest scores of 17.8 for information (Korsakoff patients $=15.2$ ) and 51.2 for vocabulary (Korsakoff patients $=47.1$ ). The alcoholics scored better than the patients with Korsakoff syndrome on tests of new learning (three-trial, paired-associate learning scores : $3.9,6.8,8.4 ;$ immediate and delayed paragraph recall : 6.6 and $5.0 ;$ cf. Table 11 . The second control group consisted of 29 (23 males and 6 females) non-alcoholic, medical inpatients or volunteers at the San Diego V.A. Medical Center (mean age $=55.3$ years, mean education $=12.9$ years $)$.

\section{Tests: remote memorv}

Television programs and past public events (recognition and simple recall). Based upon methods described previously $[22,23]$, four-choice recognition tests were constructed to sample memory for 74 television programs (Test 1) that were broadcast for a single season between 1963 and 1977 (approximately five for each year) and for 88 past public events (Test 2$)$ that occurred between 1940 and $1979(1940 \mathrm{~s}, N=19 ; 1950 \mathrm{~s}, N=18 ; 1960 \mathrm{~s}, N=24 ; 1970 \mathrm{~s}$, $N=27$ ). In addition, the public events test was given in a simple recall format (Test 3 ). 
Famous faces (uncued and cued identification). In an updated version of ALBERT, BUTTERS and LEVIN's test [15], subjects were asked to identify 130 photographs of famous people who came into prominence at various times between 1930 and $1979(1930 \mathrm{~s}, N=25 ; 1940 \mathrm{~s}, N=24 ; 1950 \mathrm{~s}, 1960 \mathrm{~s}$ and $1970 \mathrm{~s}, N=27)$. In the present version of this test, subjects first tried to identify each photograph without the benefit of cues (Test 4). Then, in a second pass through those photographs that had not been identified (Test 5), subjects were given either a single name and asked if it was correct (yes-no), or they were given three names and asked to pick the correct one (multiple-choice). Incorrect names were individuals who were prominent in the same decade and in the same general area of endeavor as the correct names and were obtained from Current Biographies. Yes-no and multiple-choice cues were alternated for the photographs that belonged to each decade.

Television programs and past public events (detailed recall). These tests asked subjects to recall as much as they could remember about the same one-season television programs and past public events sampled in the recognition and simple recall tests (Tests 6 and 7). Methods for administering such tests and scoring transcripts have been described previously $[10,12]$.

Tests: new learning capacity

Four tests were administered as outlined in Table 1 : paired-associate learning. paragraph recall, cued word recall, and picture recognition.

\section{RESULTS}

By test

Television programs and past public events (recognition and simple recall). Performance on the TV recognition test is shown for all groups in Fig. 1. N.A. and his controls performed similarly, scoring best in the most recent time period and more poorly in the more remote time periods (Fig. 1a, [12]). Patients receiving bilateral ECT (Fig. 1b, [8]) exhibited a marked impairment in recognizing names of one-season television programs broadcast one

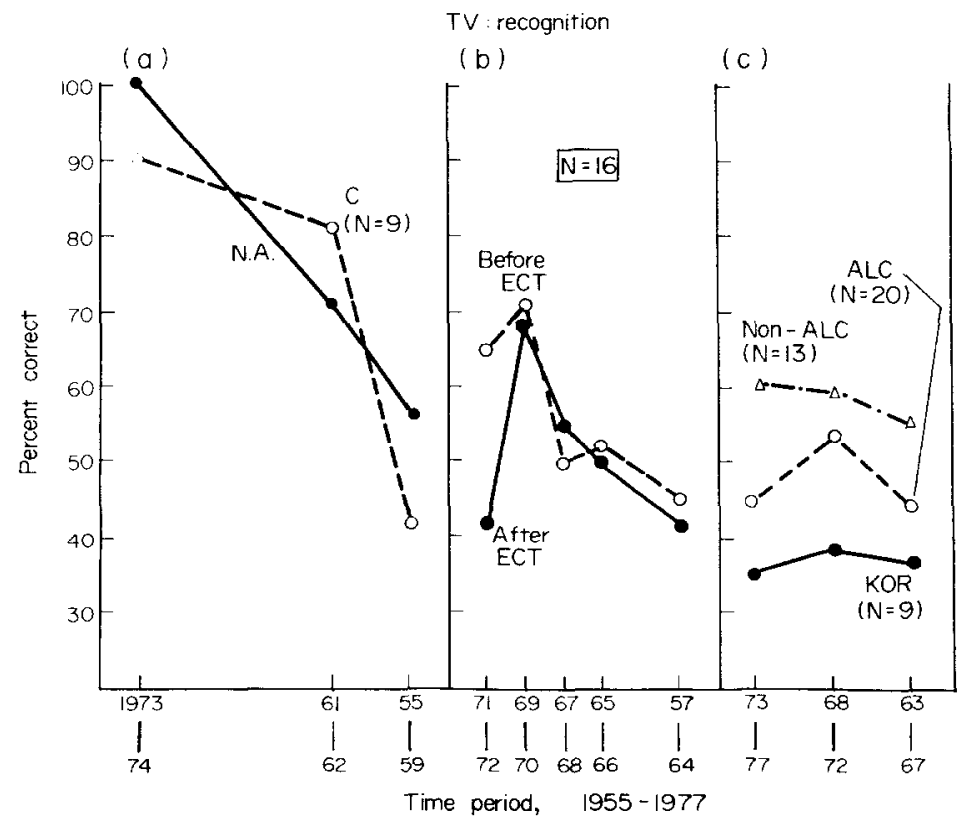

FIG. 1. Recognition memory for the names of former one-season television programs. (A) Case N.A. (B) Patients receiving bilateral ECT tested one hour after treatment No. 5. (C) Patients with alcoholic Korsakoff syndrome. 
to three years before treatment $(F=12.8, P<0.01)$, and they scored lower for this time period than for the two previous (i.e., more remote) time periods ( $F=15.9$ and $4.2, P$ s $<0.01$ ). There was no impairment for the names of television programs broadcast 4 to 7 years before treatment. Patients with Korsak off syndrome (Fig. 1c) were impaired relative to both nonalcoholic controls $(F=12.3, P<0.005)$ and to alcoholic controls $(F=4.7, P<0.05)$ across the entire time period covered by the test (simple main effects: $F \mathrm{~s}<6.9, P \mathrm{~s}<0.05$ ).

Figure 2 shows performance on the public events recognition test for all groups. N.A. (Fig. 2a) scored below the $99 \%$ confidence interval calculated for the mean of his control group for public events that occurred in the postmorbid period, subsequent to his accident (1960s and 1970 s combined : N.A. $=74.5 \%$, controls $=85.6 \% \pm 2.4 \%$ ) but scored slightly above the mean of the control group for the premorbid period, before his accident (1940s and 1950s combined: N.A. $=78.4 \%$, controls $75.5 \% \pm 3.7 \%$ ). Patients receiving bilateral ECT (Fig. 2b, [24]) performed similarly across time periods before ECT and one hour after the fifth treatment. Performance after ECT was impaired uniformly across time periods $(F=5.0$, $P<0.05)$. Patients with Korsakoff syndrome were impaired relative to alcholic controls (Fig. 2c, $F=20.2, P<0.001$ ) across the entire time period sampled by the test (simple main effects: $F \mathrm{~s}>4.8, P \mathrm{~s}<0.05$ ).

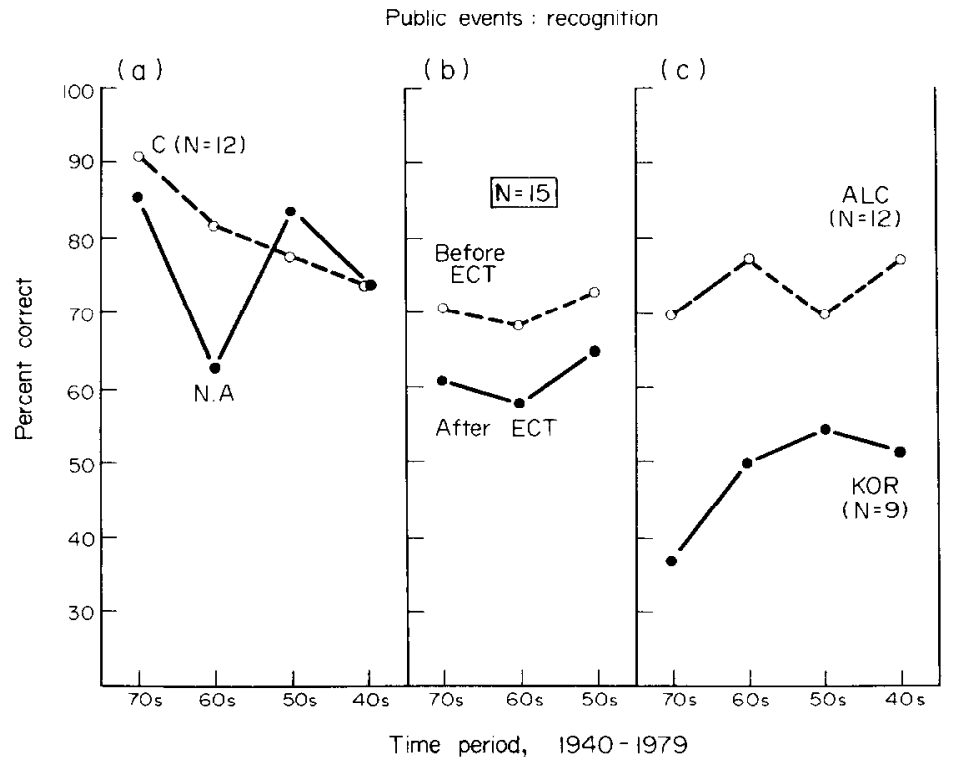

Fic. 2. Recognition memory for past public events. (A) Case N.A. (B) Patients receiving bilateral ECT tested one hour after treatment No. 5. (C) Patients with alcoholic Korsakoff syndrome.

Performance of all groups on the public events simple recall test can be seen in Fig. 3. N.A. (Fig. 3a) scored below the $99 \%$ confidence interval calculated for the mean of his control group for public events that occurred after 1960. For the period prior to 1960, N.A. exceeded the control group means. Recall of public events by patients receiving bilateral ECT (Fig. $3 \mathrm{~b}$, [25]) was impaired one hour after the fifth treatment $(F=12.3, P<0.01)$, and this impairment was particularly marked for the $1970 \mathrm{~s}(F=9.9, P<0.01)$. Patients with 


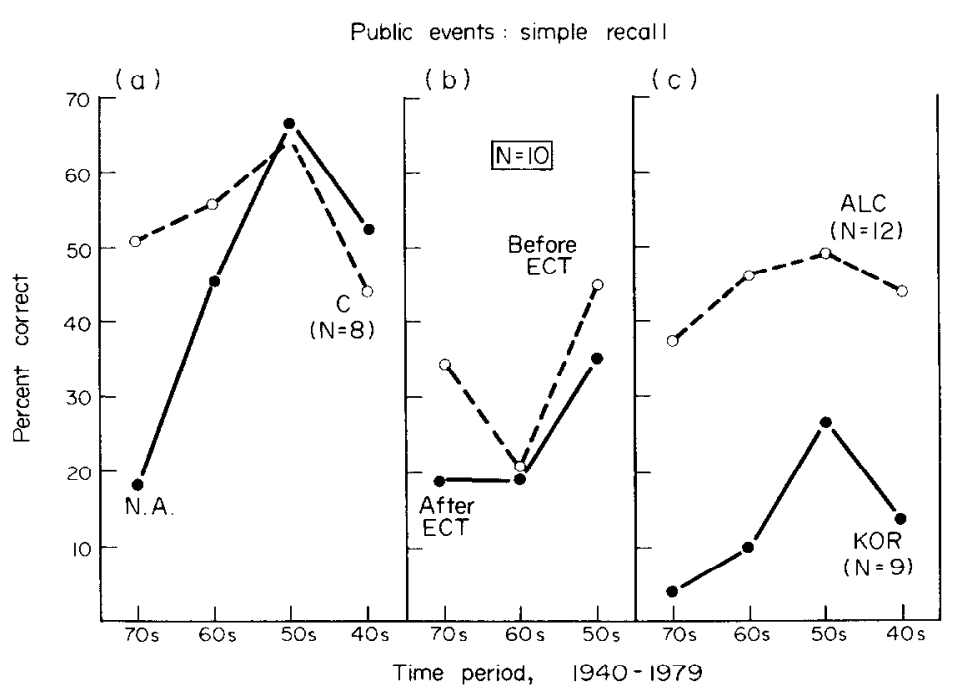

Fig. 3. Simple recall of past public events. (A) Case N.A. (B) Patients receiving bilateral ECT tested one hour after treatment No. 5. (C) Patients with alcoholic Korsakoff syndrome.

Korsakoff syndrome (Fig. 3c) were impaired relative to alcoholic controls $(F=35.1$, $P<0.001$ ) across the entire time period sampled by the test (simple main effects: $F \mathrm{~s}>8.6$, $P$ s $<0.01$ ).

Fumous faces (uncued and cued identification). Performance for all groups without cues is shown in Fig. 4. N.A.'s performance for his premorbid period was in marked contrast to his performance for the period since 1960 (Fig. 4a). He identified more faces from the 1930s and 1940s than any control subject. Yet he exhibited a profound impairment when asked to identify faces that became known during the two decades since his accident, scoring for the 1960 s and 1970 s below the $95 \%$ confidence interval calculated for the mean of his control group. He performed worse than any control subject for the 1970 s and worse than all but one control subject for the 1960s. Though yes-no and multiple-choice cues aided his performance, the cues did not compensate for his anterograde amnesia for the period since 1960. With cues, he still performed worse than any control subject for the 1970 s and worse than all but one control subject for the 1960s.

Patients receiving bilateral ECT were impaired in identifying famous faces without the benefit of cues $(F=18.5, P<0.005$; Fig. $4 \mathrm{~b})$. There was no statistical evidence for the impairment to be greater in the more recent time period (interaction of treatment $\times$ time period, $F=2.4, P>0.05$ ). Yes-no and multiple-choice cues enhanced performance both before and after ECT, and reduced the impairment associated with ECT. The difference between before-ECT and after-ECT performance with cues was not significant $(F=1.8$, $P>0.2$ ).

Patients with Korsakoff syndrome showed an extensive memory defect without cues (Fig. 4c) as well as with cues. Their defect was significant compared to alcoholic (uncued: $F=9.0, P<0.01$; cued: $F=12.8, P<0.01$ ) and non-alcoholic (uncued: $F=9.2, P<0.01$; cued: $F=13.6, P<0.01$ ) control subjects. Their defect was also temporally graded, being 


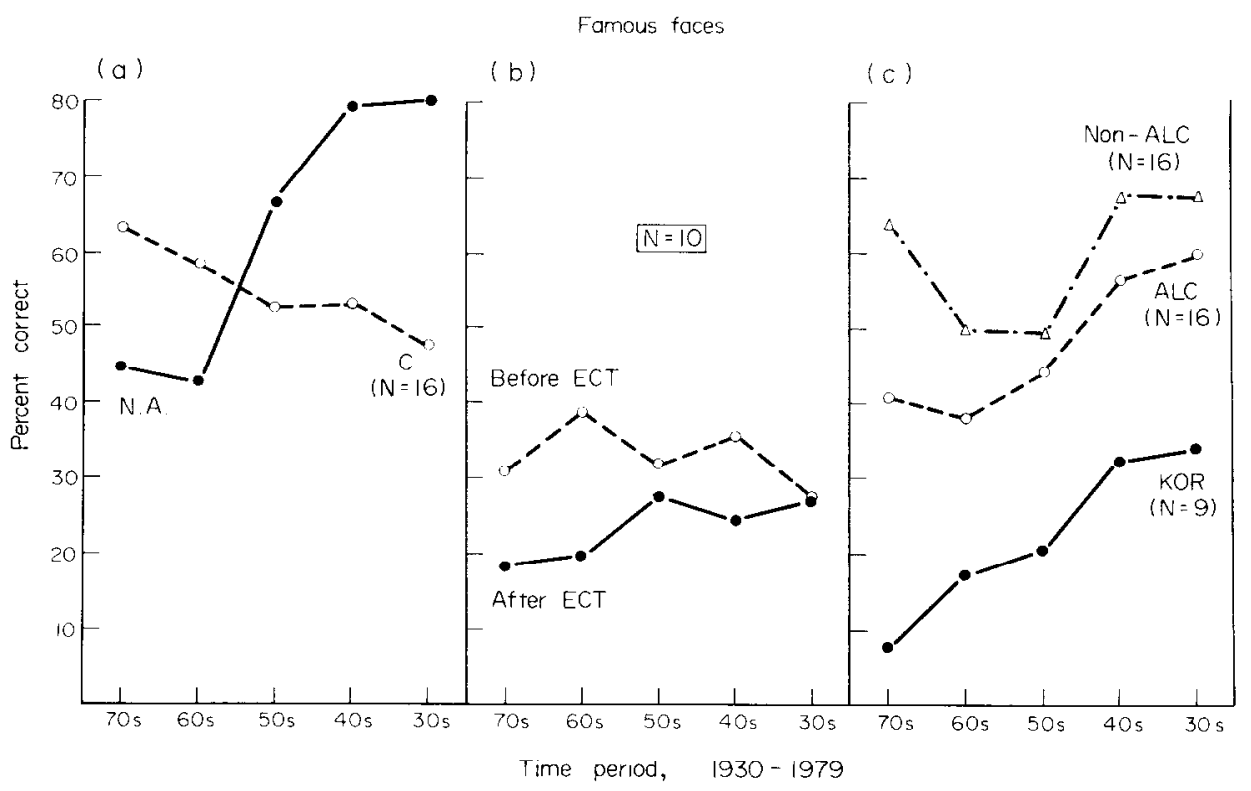

FIG. 4. Identification of famous faces without cues from the period 1930-1979. (A) Case N.A. (B) Patients receiving bilateral ECT tested one hour after treatment No. 5. (C) Patients with alcoholic Korsak off syndrome.

larger for the more recent decades (interaction of group $\times$ decades: $F \mathrm{~s}=4.8$ and 6.7 for uncued and cued identification, respectively; $P<0.001$ ); and was significant for each decade both without the benefit of cucing (simple main effects: $F \mathrm{~s}>5.1, P \mathrm{~s}<0.05$ ) and with yes-no and multiple-choice cues $\left(F \mathrm{~S}>5.0, P_{\mathrm{S}}<0.05\right)$. Thus the cues did not alleviate the amnesia. In addition, the performance of the alcoholics diverged from that of the matched non-alcoholic controls, differing significantly for the 1970 s (uncued: $F=7.0, P<0.05$; cued: $F=9.6$, $P<0.01$ ).

Television programs and past public events (detailed recall). Recall of details about past television programs and past public events is shown in Figs 5 and 6. On the TV detailed recall test (Fig. 5a, [12]), N.A. was markedly impaired for programs that broadcast since his accident in 1960 , performing below the $99 \%$ confidence interval calculated for the mean of his control group for 1973-1974, but he was normal at recalling programs that were broadcast during the five years prior to his accident. Patients receiving ECT exhibited a marked impairment in recall of programs broadcast one to two years before treatment $(F=8.5$, $P<0.01$ ), but had good recall of programs broadcast three to eight years before treatment $(1970-1972 ; F=1.0, P>0.3 ; 1967-1968: F=2.6, P>0.1)$. This temporal gradient of amnesia was reflected in a significant interaction between treatment and time period $(F=11.2$, $P<0.01)$. In addition, performance after ECT was significantly poorer for the affected recent time period than for the next more remote period $(P<0.05$, Tukey's HSD test for multiple comparisons).

Patients with Korsakoff syndrome could recall very few details about the former television programs sampled by this test (Fig. $5 \mathrm{c}$ ), and were impaired relative to alcoholic controls across the entire 15 years sampled $(F=8.5, P<0.01$; simple main effects: $F \mathrm{~s}>4.5, P \mathrm{~s}<0.05)$. 


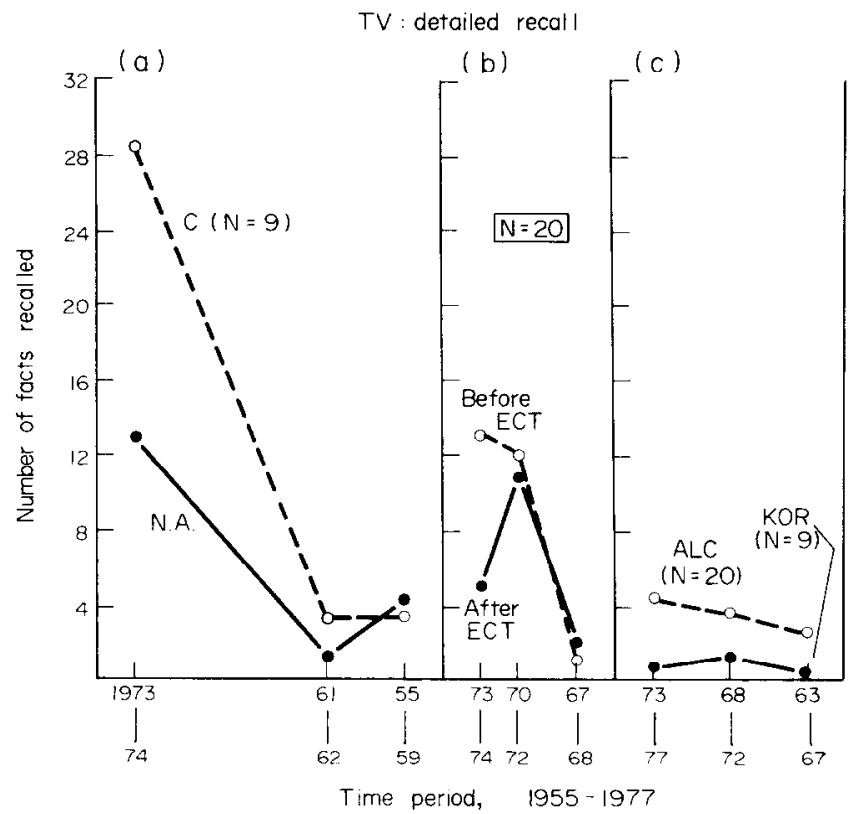

FIG. 5. Recall of details about former one-season television programs. (A) Case N.A. (B) Patients receiving bilateral ECT tested one hour after treatment No. 5. (C) Patients with alcoholic Korsakoff syndrome.

Public events: detailed recall

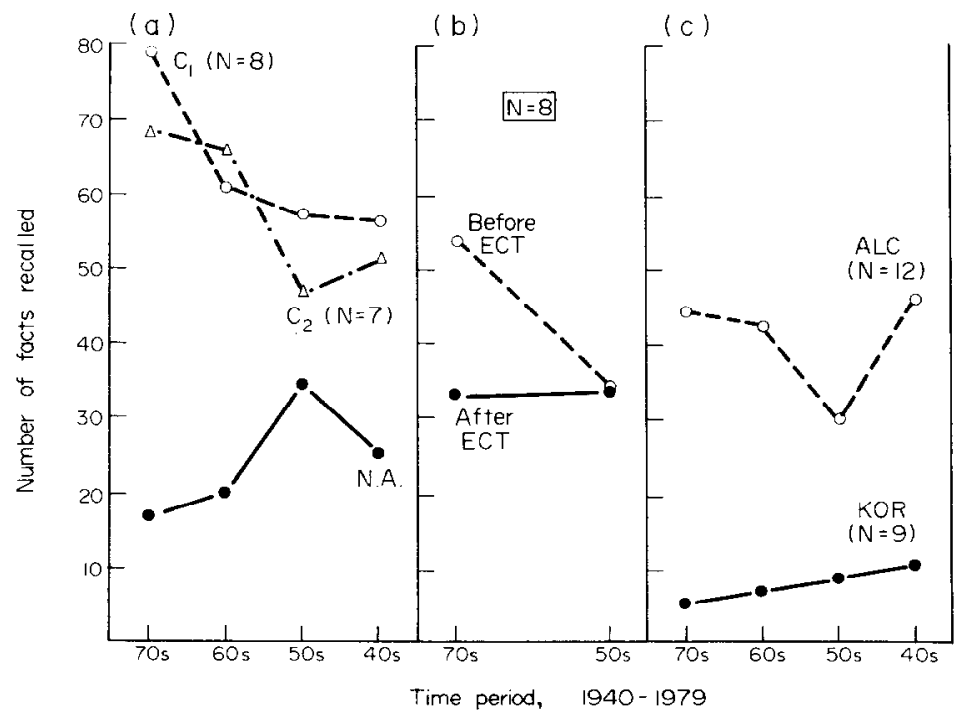

FIG. 6. Recall of details about past public events. (A) Case N.A. (B) Patients receiving bilateral ECT tested 6-10 hours after treatment No. 5. (C) Patients with alcoholic Korsakoff syndrome. 
N.A.'s performance on the public events detailed recall test was compared to two different control groups (Fig. 6a). Two control groups were used because N.A.'s education had been interrupted by his accident and his educational level is therefore lower than that of most individuals with comparable IQ test scores. Accordingly, in matching control subjects to N.A., we selected two separate groups matched for either WAIS subtest scores (mean information subtest : 23.9 vs. 22 for N.A.; mean vocabulary subtest : 64.8 vs. 66 for N.A.) or for educational level (mean $=13.0$ vs. 13 for N.A.) N.A.'s recall for the two decades following his accident was profoundly impaired relative to the recall of these control subjects, falling below the $99 \%$ confidence interval calculated for the means of the two control groups. In addition, unlike his performance on any of the other remote memory tests, N.A.'s recall of public events from the period prior to his accident was also impaired, below the $95 \%$ confidence interval calculated for the mean of the control groups.

Performance of patients receiving bilateral ECT is presented in Fig. 6b. These patients were markedly impaired in recalling events from the 1970 s $(F-8.9, P<0.01)$, but were unaffected in their recall of events from the 1950s $(F<1, P>0.3)$. There was a significant interaction of treatment and time period $(F=6.1, P<0.02)$.

The patients with Korsak off syndrome (Fig. 6c) could recall few details about public events sampled by this test; and, compared to the alcoholic controls, were markedly impaired over the entire time period ( $F=35.8, P<0.001$; simple main effects: $F \mathrm{~S}>12.1, P \mathrm{~s}<0.01)$. In addition, their pattern of performance differed significantly from that exhibited by the alcoholic controls (interaction of group $\times$ decade: $F=5.7, P<0.005$ ).

New learning capacity. Performance of the different patient groups on tests of anterograde amnesia is shown in Table 1. The severity of the anterograde deficit across the four tests was comparable among groups. This similarity in new learning capacity contrasted with the marked difference in remote memory capacity among these same groups.

Table 1. Severity of anterograde amnesia

\begin{tabular}{|c|c|c|c|}
\hline Test description & N.A.* & $\begin{array}{l}\text { Patient group } \\
\text { ECT } t\end{array}$ & Korsakoff \\
\hline $\begin{array}{l}\text { A. Paired-Associate Learning, } 10 \text { noun-noun pairs [12] } \\
\text { (Number correct out of } 10 \text { on each of } 3 \text { trials) }\end{array}$ & $0,0,2$ & $\begin{array}{l}1.1,3.4,4.6 \\
(N=8)\end{array}$ & $\begin{array}{c}0.6,0.9,2.1 \\
(N=9)\end{array}$ \\
\hline $\begin{array}{l}\text { B. Paragraph Recall [12] (Number of segments recalled, } \\
\text { at immediate test/after } 12 \text { min delay) }\end{array}$ & $4.5 / 0$ & - & $\begin{array}{c}4.1 / 0 \\
(N=9)\end{array}$ \\
\hline $\begin{array}{l}\text { C. Cued Word Recall, } 36 \text {-word list [56] } \\
\text { (Number correct out of } 36 \text {, corrected for guessing) }\end{array}$ & 8.8 & $\begin{array}{c}8.4 \\
(N=8)\end{array}$ & $\begin{array}{c}6.6 \\
(N=6)\end{array}$ \\
\hline $\begin{array}{l}\text { D. Picture Recognition, } 120 \text { pictures }[45] \\
\text { (d' } \pm \text { S. E., after } 10 \text { min delay) }\end{array}$ & 一 & $\begin{array}{l}1.5 \pm 0.16 \\
(N=9)\end{array}$ & $\begin{array}{l}1.74 \pm 0.15 \\
(N=7)\end{array}$ \\
\hline
\end{tabular}

*N.A. was not tested on picture recognition because his chronic amnesia is largely for verbal material.

tDifferent ECT patients were used for each memory test: for A, testing occurred six to ten hours after the fifth treatment; for C, testing occurred 50-90 min after each of the first four treatments; for $D$, testing occurred two hours after the fourth and fifth treatments. The score for Test D is the most useful estimate of the amnesia associated with ECT because it was given very close to the time during the course of treatment as the remote memory tests. Scores for Tests $\mathrm{A}$ and $\mathrm{C}$ are more conservative estimates of their amnesia because these tests were given at a time when amnesia is somewhat less severe [21]. 


\section{By patient group}

Case N.A. As measured by six of seven tests, his remote memory appeared intact for the premorbid period, prior to his accident in 1960 . However, N.A.'s detailed recall of public cvents (Fig. 6a) was impaired relative to two different control groups for the premorbid period, though this defect was not nearly as severe as for the postmorbid period (1960s and 1970 s). Although in a previous test of detailed recall of public events, N.A.'s performance for the 1950 s was intact [12], the present findings suggest that N.A.'s memory for the premorbid period may not be entirely normal. Possible explanations of N.A.'s difficulty in recalling details about the 1940s and the 1950s will now be considered.

First, it is possible that compared to recognition or simple recall tests, the detailed recall test permits a more fine-grained estimate of remote memory capacity [12] and that N.A.'s defect in remote memory for the 1940s and 1950s on this test reflects true retrograde amnesia. Thus, the three different public events tests given to N.A. in the present study (recognition, simple recall, detailed recall, ordered with respect to our judgment of information demand; Figs $2 \mathrm{a}, 3 \mathrm{a}$ and $6 \mathrm{a}$ ) revealed progressively more remote memory impairment, which extended to premorbid memory in the case of detailed recall.

Second, it is possible that N.A.'s impaired performance for the premorbid period may occur as a result of his anterograde amnesia. Since N.A.'s anterograde amnesia isolates him considerably from current events, there can be little incorporation into memory of new information and there can be little elaboration or reorganization of previously established memories based upon new information. Accordingly, N.A.'s poor recall of events from the 1940 s and the 1950 s could reflect his social isolation and failure to add new information since 1960 , rather than a true loss of previously established memory.

Some support for this "social isolation" hypothesis comes from previous studies of remote memory in normal subjects $[22,26]$. In one study, [26] subjects in their 30's at the time of testing recalled more about past public events from all time periods (1890s-1960s) than did subjects in their 20's. In the other study [22], subjects who averaged 25 years of age at the time of testing did better $(75+3 \%$ correct) on questions about events that occurred during their first 13 years of life than did subjects who were 15-16 years of age at the time of testing $(42 \pm 3 \%$ correct). The critical point from these two studies is that subjects acquire some information about public events after they occur. N.A., however, became isolated from public events at the age of 22 years, and he could not subsequently have acquired as much information about public events that had occurred when he was young as could have normal subjects from his generation.

There is another way in which anterograde amnesia could be responsible for N.A.'s impairment in recall from the premorbid period. Successful recall of details from remote memory depends in part on the selcction and employment of appropriate scarch strategies that help the subject create specific contexts to recover past memories, especially for information that is difficult to retrieve [27]. Recall from recent memory has also been shown to benefit from successful selection and establishment of specific "perspectives" or search strategies by which information can be reconstructed [28]. Anterograde amnesia could interfere with the ability to maintain and keep track of such strategies, particularly when they are used to sustain or direct memory search for prolonged periods of time. However, the finding that retrograde amnesia following ECT can be restricted to the few years prior to treatment, even for tests of detailed recall (Figs 5b and 6b), would appear to discount this notion. If N.A.'s poor detailed recall is to be attributed to a problem with search strategies, 
the impairment would have to be part of an additional defect superimposed on his amnesia that is not shared by patients receiving ECT.

Whatever the correct interpretation of N.A.'s poor detailed recall of past public events from the period before his accident, it should be emphasized that this impairment was not as severe as his impairment for the period following his accident and that no impairment was observed at all for six other tests of remote memory, including a test of detailed recall of former one-season television programs (Fig. 5a).

Patients receiving ECT. Before ECT, the pattern of performance across time periods differed considerably among tests. After ECT, the pattern of impairment appeared to be related to the pattern of performance before ECT. Thus, on all three tests for which performance before ECT yielded a forgetting curve, (Figs. 1b, 5b, and 6b), ECT produced temporally-graded retrograde amnesia. On tests for which performance before ECT was similar across all time periods (Figs $2 \mathrm{~b}$ and $4 \mathrm{~b}$ ), ECT produced a remote memory impairment that affected all past time periods equally. On the test that yielded irregular performance before ECT (Fig. 3b), ECT selectively impaired memory for the 1970s. On this test, before ECT performance was better for the 1970s than for the 1960s, and temporally-graded retrograde amnesia did occur across this portion of the test.

The finding that retrograde amnesia following bilateral ECT can be temporally graded has been taken as confirmation of RIBOT's Law [29] that memories grow more resistant to disruption as time passes after learning. This change that occurs as time passes could provide a basis for gradual reorganization and restructuring [30], and for the development of schemata [31], that have been suggested to occur in normal memory with the passage of time. By this view there develops gradually after learning a representation of the original experience that has lost detail through forgetting, but whose organization has become more abstract, schematized and more resistant to disruption.

Several alternative formulations that attempt to explain these findings without postulating the development of resistance with the passage of time have been considered in detail elsewhere and found to be inconsistent with the data [10]. Thus, temporal gradients of retrograde amnesia like those observed here cannot be explained by sampling bias in test construction, or as a simple inability to perform well after ECT, or by a selective effect of ECT on material that will be quickly forgotten and that is necessarily most abundant in recent time periods.

Temporally-graded retrograde amnesia was not obscrved for memory tests that beforc ECT yielded similar scores across all time periods. As discussed previously [32], development of resistance in long-term memory might be related to the course of normal forgetting, such that resistance develops while forgetting occurs. If this view is correct, then temporally-graded retrograde amnesia should be easiest to observe with tests that produce a forgetting curve in normal memory. Those tests that do not yield a forgetting curve in normal memory might actually be assessing memories from different time periods that have been forgotten to about the same degree or have not heen forgotten at all. These memories would have therefore developed a similar degree of resistance to disruption, or no resistance to disruption; and under these conditions temporally-graded retrograde amnesia would not be expected to occur.

Patients with alcoholic Korsakoff syndrome. For each of seven tests of remote memory, patients with Korsakoff syndrome demonstrated a severe and extensive impairment that included the most remote time period sampled by each test. Furthermore, for six of the seven remote memory tests their impairment appeared temporally graded, affecting recent time 
periods to a greater extent than more remote time periods. The only exception was detailed recall of former one-season television programs (Fig. 5c) for which performance was too poor to permit any clear pattern to emerge.

Previous investigations of remote memory impairment in patients with Korsakoff syndrome ([2, 13-16], see Table 2$)$ have led to disagreement concerning both the extent and pattern of the impairment. These two issues now seem resolved. With respect to the extent of remote memory impairment, our findings indicate that this impairment extends to the most remote time period sampled, in agreement with the results of three previous studies $[13,15$, 16]. Although two different studies $[2,14]$ reported patients with Korsakoff syndrome to have an extensive remote memory impairment that did not include the most remote time periods, methodological problems with these studies weaken that interpretation $[5,15]$. Taken together, the available evidence from all studies of remote memory impairment in patients with Korsakoff syndrome strongly suggests that this defect in remote memory is extensive and covers the majority of their adult life.

The present findings also bear on the issue of whether this impairment is equally severe for all affected time periods or whether it is temporally graded. In agreement with several previous studies $[2,14-16]$ the present results indicate that remote memory impairment in Korsak off syndrome is temporally graded. It is greatest in the recent time periods and smaller in more remote time periods. One previous study [13] found remote memory impairment to be constant across all time periods tested; but as discussed elsewhere [5, 15,33], performance on this test was confounded by a floor effect that could have masked a temporally-graded impairment. Accordingly, the available evidence argues strongly that remote memory impairment in patients with Korsakoff syndrome is temporally graded.

The finding that the remote memory impairment exhibited by patients with Korsakoff syndrome was different from that exhibited by the other amnesic patients raised the possibility that their impairment might depend on certain unique features of the Korsakoff syndrome; specifically, the insidious onset of their disease and the presence of cognitive deficits other than amnesia that could impair performance on remote memory tests.

Thus Korsak off syndrome occurs with an insidious onset, which is accompanied by the gradual appearance of anterograde amnesia [34] and which might be expected to result in impaired performance on remote memory tests for the time period during which the disease was developing. The present findings and previous work [33] have confirmed this idea by showing that chronic alcoholics as well as patients with Korsakoff syndrome consistently performed more poorly for the most recent time period than for a more remote time period. Control subjects did not show this pattern. Thus, alcoholics seem to exhibit a gradual decline over the years in the ability to acquire new information. In the case of the patient eventually identified as having Korsakoff syndrome, who develops more severe anterograde amnesia than the alcoholic, this gradual change could be expected to result in an extensive, temporally-graded impairment of remote memory.

The other factor that could contribute to the remote memory impairment of patients with Korsakoff syndrome is the occurrence of deficits in cognitive function. For example, they have difficulty with tests of concept formation and problem solving $[35,36]$, perceptual processing [35, 37-39], and rapid switching of cognitive set [35, 40]; and they are impaired on the Halstead category test [41]. More importantly, perhaps, Cermak has reported patients with Korsak off syndrome to have an impairment in retricval from semantic memory [42] and in retrieval strategies for recently acquired information [43]; reconstructive deficits that might contribute uniformly to remote memory impairment across all past time periods. 


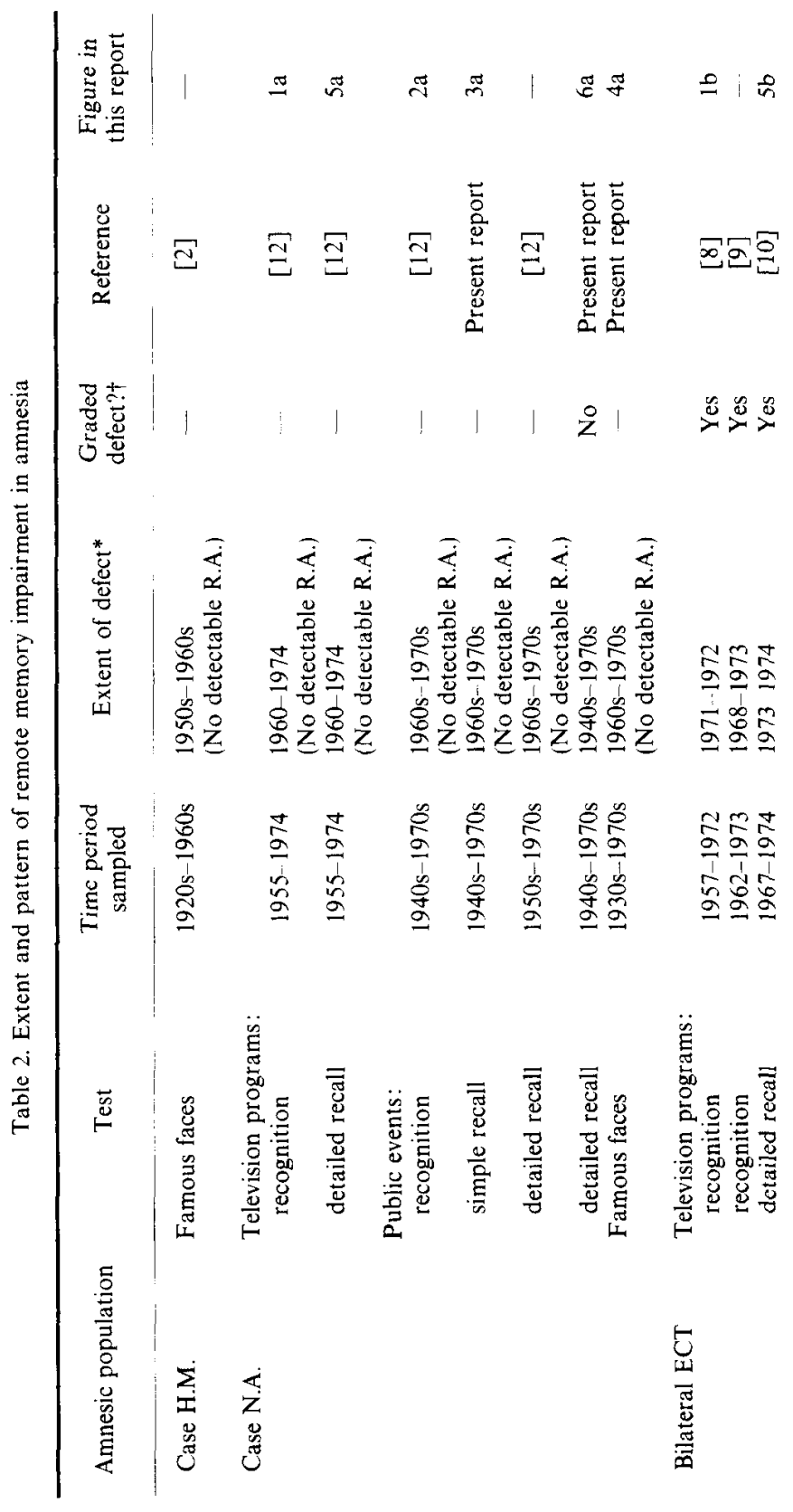




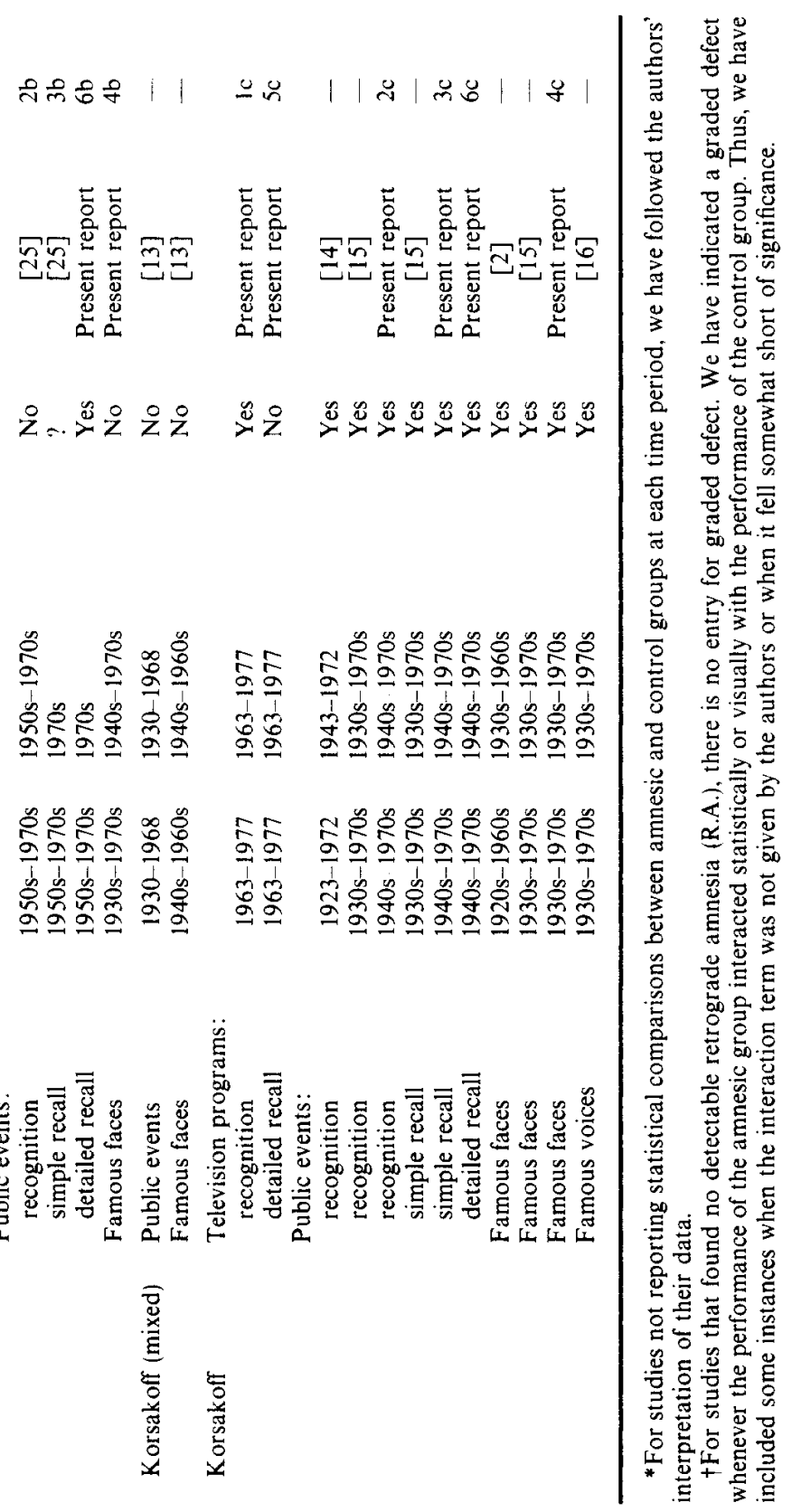


In summary, the extent and pattern of remote memory impairment exhibited by patients with Korsakoff syndrome contrasted with the performance of case N.A. and paticnts receiving bilateral ECT. The results suggest a role for (1) progressive anterograde amnesia, which exerts a greater effect on recent years than on more remote years and which might explain the temporally-graded pattern of their remote memory impairment; and (2) cognitive deficits that affect all past memories equally, and that might explain the extensiveness of their remote memory impairment.

\section{DISCUSSION}

The results of the present tests, together with the results of previous studies of remote memory and amnesia, demonstrate clearly that etiologically-distinct amnesic groups differ markedly with respect to the extent and pattern of remote memory impairment (Table 2). In the present study, these differences in remote memory occurred despite similarity in the severity of anterograde amnesia among the patient groups. Thus the severity of anterograde amnesia can provide no explanation for the profound differences among the same groups in remote memory capacity. Accordingly, the extensive remote memory impairment exhibited by patients with Korsak off syndrome is not inextricably coupled to anterograde amnesia. Furthermore, the differences in remote memory impairment that have been observed in amnesia must mean that amnesia can take qualitatively different forms.

It should be noted that qualitative differences are also known to exist among amnesic groups in the domain of anterograde amnesia. In studies designed to assess forgetting rates in anterograde amnesia, patients with Korsakoff syndrome and case N.A. differed from the noted patient H.M. and from patients receiving bilateral ECT. N.A. and patients with Korsak off syndrome exhibited a normal rate of forgetting for material they were able to learn $[44,45]$, while H.M. and patients receiving ECT exhibited an accelerated rate of forgetting $[45,46]$. This finding has suggested that the "stage" of memory function disrupted in N.A. and in Korsakoff syndrome is different than in the other groups, and it provides support for the present view that amnesia is fundamentally a non-unitary disorder $[45,46]$. The remainder of the discussion takes amnesia as a non-unitary disorder and considers the two identified forms of remote memory dysfunction, temporally-limited retrograde amnesia and extensive remote memory impairment, as distinct entities.

Temporally-limited retrograde amnesia. Retrograde amnesia, ranging from several months to a few years, has been described clinically in cases H.M. and N.A. $[6,12]$, and in other surgical and head trauma patients $[6,7,47]$. In the case of patients receiving ECT, objective evidence for temporally-limited retrograde amnesia has been obtained repeatedly with formal tests (Table 2). As discussed previously [10, 32], temporally-limited retrograde amnesia implies a process in normal memory whereby recently acquired memories gradually become more resistant to disruption with the passage of time. In addition these ideas provide support for the hypothesis that amnesia reflects a consolidation defect, whereby an impairment occurs in the formation of new memories and in the recall of memories that have been formed recently $[1,4]$. Although the term consolidation has often been used to refer to a process of information transfer from a labile short-term store to a more stable long-term store in the minutes, hours, or perhaps days after learning, it is now widely held that gradual reorganization and restructuring can occur in long-term memory for a period of years [30]. Accordingly, a brain injury that interferes with this process would result in a defect in the 
formation of new stable memories (anterograde amnesia) and a concomitant defect in accessing information that was undergoing this gradual process when the brain injury occurred (retrograde amnesia).

In support of this idea, studies of experimental amnesia in animals [47] as well as reports of traumatic amnesia in man [48] have stressed that anterograde amnesia and temporallylimited retrograde amnesia occur together. In the case of human traumatic amnesia, more severe anterograde amnesia is associated with more prolonged retrograde ammesia [48]. WICKLEGREN has explicitly suggested that anterograde and brief retrograde amnesia involve a common mechanism [49].

We suggest that temporally-limited retrograde amnesia typically occurs in the amnesic syndrome and that its extent, up to a few years, correlates with the severity of anterograde amnesia. In Korsakoff syndrome, such a pattern of retrograde amnesia would necessarily be obscured by extensive remote memory impairment. Moreover, since the extensive remote memory impairment exhibited in Korsakoff syndrome seems fundamentally different from temporally-limited retrograde amnesia, the relationship that anterograde amnesia has with temporally-limited retrograde amnesia need not imply a similar relationship between anterograde amnesia and extensive impairment of remote memory.

Premorbid vs. postmorbid memory and theories of amnesia. The finding that retrograde amnesia can be restricted to a few years and that premorbid memory can be less affected than postmorbid memory has several important implications for the neuropsychology of memory. First, the affected brain regions of such patients are not the permanent sites of memory storage. Instead, the affected structures appear to constitute an essential neuroanatomic system for the formation, maintenance, or retrieval of new memories. Second, the findings rule out a general retrieval explanation for all amnesias. A general retrieval defect should involve memory for all past events and not just memory for events that have occurred since the onset of amnesia. It should be noted that retrieval explanations (e.g. $[17,50]$ ) derive largely from work with patients with Korsakoff syndrome who, as we shall discuss below, have not demonstrated this distinction between premorbid and postmorbid memory.

One version of a general retrieval theory based on patients with Korsakoff syndrome [17] has supposed that amnesic patients are unable to retrieve from episodic, autobiographical memory. Informal observations of N.A. or of patients receiving ECT could appear consistent with this idea because they have little difficulty with use of language or social skills, which involve semantic information; yet they cannot remember the episodic events of daily life. We submit, however, that this observation relates to the distinction between premorbid and postmorbid memory, and not to a distinction between semantic and episodic memory. By our view, the ability of amnesic patients to engage normally in conversations and other dayto-day activities is due to the preservation of premorbidly acquired information, be it semantic or episodic. Indeed, there appear to be several problems with the hypothesis that amnesic patients cannot retrieve from episodic memory. First, amnesic patients have welldocumented difficulties in acquiring such semantic information as new vocabulary words and new names. Second, like other general retrieval theories, this one can offer no explanation for the difference between premorbid and postmorbid memory observed in cases H.M. [2] and N.A., and in patients receiving ECT. Finally, even in patients with Korsakoff syndrome who, as we shall discuss below, have difficulty recalling previously established memories, the deficit is not limited to personal, episodic memory. Their deficit includes nonautobiographical, general information about former television programs, past public events, and famous public figures. 
The distinction between premorbid and postmorbid memory, and the facts of retrograde amnesia, seem to indicate a role for diencephalic and bitemporal structures in the formation of new memories, and in the elaboration or maintenance of such memories for a few years in a manner that permits their successful retrieval. Studies of forgetting rates in anterograde amnesia, discussed above, suggests in addition that these brain regions may contribute in different ways to accomplishing this function.

Extensive remote memory impairment. In contrast to the relatively brief retrograde amnesias observed for N.A. and for patients receiving ECT, patients with Korsakoff syndrome exhibited an extensive remote memory impairment on all seven tests. This difference occurred despite the fact that the severity of the anterograde amnesia deficits exhibited by these groups was quite comparable. The existence of two kinds of remote memory impairment, as well as two kinds of anterograde deficit (see above), suggests that there may be at least two qualitatively distinct amnesic syndromes corresponding to the different areas of the brain where damage results in memory impairment. Thus, the nature of the deficit would differ according to whether the patient suffers dysfunction of either the medial temporal region (H.M. and perhaps patients receiving ECT [51] or of the diencephalon (patients with Korsakoff syndrome and N.A.). This idea raisés the possibility that the locus of the brain damage specifies both the nature of the anterograde deficit and the extent of remote memory impairment. However, if the differences among amnesic groups in remote memory impairment are to be understood in terms of differences in locus of lesion, then case N.A. with diencephalic damage should, like Korsakoff patients, have extensive remote memory impairment. Although N.A.'s impaired detailed recall of past public events (Fig. 6a) is consistent with this notion, his performance on the other tests differed substantially from that of patients with Korsakoff syndrome. Indeed, he exhibited intact premorbid memory on six of the seven tests.

Perhaps a better way to understand the differences in remote memory impairment among different amnesic groups is to suppose that extensive remote memory impairment is an entity that is superimposed upon amnesia. Patients with Korsakoff syndrome have extensive remote memory impairment, and, as discussed above, have deficits in cognitive abilities not shared by other amnesic patients. In addition, the brain lesions associated with their disease can be extensive compared to that of other amnesic groups, often involving a number of structures in the diencephalic midline, cerebellum, and cortex. Accordingly, patients with Korsakoff syndrome might have an underlying memory disorder common to other amnesias but, by virtue of the extent of their brain lesions, have other superimposed deficits that impair performance on a variety of tasks, including tests of remote memory. By this view, the locus of brain lesions specifies the nature of the anterograde deficit, and the extent of brain lesions specifies the extent of remote memory impairment. The poor remote memory performance of post-encephalitic patients is consistent with this view. Like H.M., post-encephalitic patients have considerable temporal lobe damage [52]; but, like patients with Korsakoff syndrome, they often have additional damage to other areas of the brain (in their case, cingulate gyrus and posterior orbital frontal cortex [53]). These patients, in contrast to H.M. and patients receiving ECT, are reported to have an extensive remote memory impairment like that associated with Korsakoff syndrome [54]. It should be noted that MAIR, WARRINGTON and WEISKRANTZ [55] reported two patients with Korsakoff syndrome who at autopsy were found to have rather restricted lesions but who had nevertheless displayed extensive remote memory impairment. In this report, too, the patient with the more extensive pathology (in thalamus and cerebral cortex) had exhibited more extensive remote memory impairment. 
Taken together, these ideas lead to the suggestion that the locus and extent of brain lesions are separate factors that determine the particular pattern and extent of both anterograde amnesia and remote memory impairment as observed in etiologically-distinct amnesic groups. These ideas lead also to the prediction that other amnesic patients who exhibit extensive remote memory impairment will, with careful testing of cognitive abilities, exhibit reconstructive deficits.

\section{SUMMARY}

The present studies suggest several general conclusions about amnesia and the neuropsychology of memory: (1) amnesia is a non-unitary disorder. (2) Brief retrograde amnesia and extensive remote memory impairment are distinct entities. Brief retrograde amnesia is present whenever amnesia occurs, and its extent is correlated with the severity of anterograde amnesia. Extensive remote memory impairment is not inextricably tied to the amnesic syndrome and may be related to certain other cognitive deficits that impair the ability to reconstruct past memories. (3) The characteristics of amnesia are determined by both the locus and extent of brain lesions. The locus (diencephalic or bitemporal) specifies the nature of the anterograde deficit, and the extent specifies the extent of remote memory impairment. (4) The brain regions affected in amnesia appear to be specialized for the formation of new memorics, and for their elaboration and maintenance for a few years after learning in a manner that permits their successful retrieval. (5) As time passes after learning some information in memory becomes more resistant to disruption, through a process that continues for years.

Acknowledgements - Supported by the Medical Research Service of the Veterans Administration and by NIMH Grant MH 24600. We thank Pamela Slater, Mary Fox, and Anne Reilly for research assistance, Dr. Marilyn Albert of the Boston V.A. Hospital for providing us with a copy of her famous faces test, and Dr. Richard Weiner of the Durham V.A. Hospital for testing four patients on the famous faces test. We also thank Dr. Stuart Zola-Morgan for commenting on earlier drafts of the paper

\section{REFERENCES}

1. Milner, B. Disorders of learning and memory after temporal lobe lesion in man. Clinical Neurosurgery 19. 421-446, 1972.

2. MARSLen-Wilson, W. D. and Teuber, H. L. Memory for remote events in anterograde amnesia: recognition of public figures from news photographs. Neuropsychologia 13, 353-364, 1975.

3. Warrington, E. K. and Weiskrantz, L. An analysis of short-term and long-term memory defects in man. In The Physiological Basis of Memory, J. A. Deutsch (Editor). Academic Press, New York, 1973.

4. Squire, L. R. The hippocampus, space and amnesia. Behav. Brain Sci. 2, 514-515, 1979.

5. SQuire, L. R. and CoHEN, N. J. Remote memory, retrograde amnesia, and the neuropsychology of memory. In Human Memory and Amnesia, L. Cermak (Editor). Lawrence Erlbaum, Hillside, New Jersey, 1981, in press.

6. Scoville, W. B. and Milner, B. Loss of recent memory after bilateral hippocampal lesions. J. Neurol., Neurosurgery Psychiat. 20, 11-21, 1957.

7. Penfield, W. and Milner, B. Memory deficit produced by bilateral lesions in the hippocampal zone. Archs Neurol. Psychiat. 70, 475-497, 1958.

8. Squire, L. R., Slater, P. C. and Ciface, P. M. Retrograde amnesia: Temporal gradient in very long-term memory following electroconvulsive therapy. Science 187, 77-79, 1975.

9. SQuire, L. R., Chace, P. M. and Slater, P. C. Retrograde amnesia following electroconvulsive therapy. Nature 260, 775-777, 1976.

10. Squire, L. R. and Cohen, N. Memory and amnesia: resistance to disruption develops for years after learning. Behav. neural Biol. 25, 115-125, 1979.

11. Rozin, P. The psychobiological approach to human memory. In Neural Mechanisms of Learning and Memory, M. R. Rosenzweig and E. L. Bennett (Editors). MIT Press, Cambridge, 1976.

12. Squire, L. R. and Slater, P. C. Anterograde and retrograde memory impairment in chronic amnesia. Neuropsychologia 16, 313-322, 1978. 
13. SANDERS, H. I. and WARRINGTON, E. K. Memory for remote events in amnesic patients. Brain 94, 661-668, 1971 .

14. Selzer, B. and BENSON, D. F. The temporal pattern of retrograde amnesia in Korsakoff's disease. Neurology $\mathbf{2 4}$, 527-530, 1974.

15. Albert, M. S., Butters, N. and Levin, J. Temporal gradients in the retrograde amnesia of patients with alcoholic Korsak off's disease. Archs Neurol. 36, 211-216, 1979a.

16. Meudell, P. R., Northern, B., SNOwden, J. S. and NF.ARY, D. Long-term memory for famous voices in amnesia and normal subjects. Neuropsychologia 18, 133-139, 1980.

17. Kinsbourif, M. and WoOD, F. Short-term memory processes and the amnesic syndrome. In Short-Term Memory, D. Deutsch and J. A. Deutsc h, (Editors). Academic Press, New York, 1975.

18. Teuber, H. L., Milner, B. and Vaughan, H. G. Persistant anterograde amnesia after stab wound of the basal brain. Neuropsychologia 6, 267-282, 1968.

19. Squire, L. R, and MoOre, R. Y. Dorsal thalamic lesion in a noted case of chronic memory dysfunction. Almh Neurol. 6, 503-506, 1979.

20. SQuire, L. R. Electroconvulsive therapy and memory loss. Am. J. Psychiat. 134, 997-1001, 1977.

21. SQuire, L. R. Neuropsychological effects of ECT. In Electroconvulsive Therapies: Biological Foundations and Clinical Application, W. B. Essman and R. Abrams (Editors). Spectrum Publications, 1981, in press.

22. Souire, L. R. Remote memory as affected by aging. Neuropsychologia 12, 429-435, 1974.

23. SOUIRE, L. R. and Si.ATER, P. C. Forgetting in very long-term memory as assessed by an improved questionnaire technique. J. exp. Psychol.: Human Learning and Memory 104, 50-54, 1975.

24. Squire, L. R. A stable impair ment in remote memory following electroconvulsive therapy. Neuropsychologia 13, $51-58,1975$.

25. Squire, L. R., Sla ter, P. C. and Mili.er, P. L. Retrograde amnesia following ECT: long-term follow-up studies. Archs gen. Psychiat., 38, 89-95, 1981.

26. Botwinick, J. and Storandt, M. Memory, Related Functions, and Age. Charles Thomas, Springfield, Illinois, 1974.

27. Williams, M. Search: some observations on the process of retrieval from very long term memory. Unpublished Ph.D. Thesis, University of California, San Diego, 1977.

28. Anderson, R. C. and Pichert, J. W. Recall of previously unrecallable information following a shift in perspective. J. Verbal Learning and Verbal Behavior 17, 1-12, 1978.

29. RibOt, T. Diseases of Memory. Appleton, New York, 1882.

30. Norman, D. A. and Rumelhart, D. E. Explorations in Cognition, W. H. Freeman, San Francisco, 1975.

31. Bartlett, F. C. Remembering. Cambridge University Press, Cambridge, 1932.

32. Squire, L. R. and Schla PFER, W. T. Biochemical aspects of learning, memory and its disorders. In Memory and memory disorders: A biological and neurological perspective. Handbook of Biological Psychiatry, Pt. IV, H. M. van Pragg, M. H. Ladfr, O. J. Rafaelsfen and E. J. Sachar (Editors). Marcel Dekker, 1981, in press.

33. Butters, N. and Al.Bert, M. S. Processes underlying falures to recall remote events. In Human Memory and Amnesia, L. CFrmak (Editors). Lawrence Erlbaum, Hillside, New Jersey, 1981, in press.

34. Ryan, C., Butters, N. and MONTGOMERY, L. Memory deficits in chronic alcoholics: continuities between the intact alcoholic and the alcoholic Korsakoff patient. In Alcohol Intoxication and Withdrawal. H. BEGLFiTER and B. KisSin (Editor). Plenum Press, New York, 1979.

35. Talland, B. A. Deranged Memory. Academic Press, New York, 1965.

36. OSCAR-BERMAN, M. Hypothesis testing and focusing behavior during concept formation by amnesic Korsakoff patients. Neuropsychologia 11, 191-198, 1973.

37. Oscar-Berman, M., Goodglass, H. and Cherlow, D. G. Perceptual laterality and ionic recognition of visual materials by Korsakoff patients and normal adults. J. comp. physiol. Psychol. 82, 316-321, 1973.

38. Glosser, G., Butters, N. and Kaplan. E. Visuoperceptual processes in brain damaged patients on the digit symbol substitution test. Int. J. Neurosci. 1, 59 66, 1977.

39. Kapur, N. and Butters, N. An analysis of visuoperceptive deficits in alcoholic Korsakoffs and long-term alcoholies, J. Studies on Alcohol. 38, 2025-2035, 1977.

40. Glosser, G., Butrers, N. and SamuFı.S, I. Failures in information processing in patients with Korsakoff's syndrome. Neuropsychologia 14, 327-334, 1976.

41. MCAndrew, J., Berkey, B. and Matthews, C. The effects of dominant and non-dominant unilateral ECT as compared to bilateral ECT. Am. J. Psychiat. 124, 483-490, 1967.

42. Cermak, L. S., Reale, L. and Baker, E. Alcoholic Korsakoff patients' retrieval from semantic memory. Brain and Language 5, 215-226, 1978.

43. Cermak, L. The long and short of it in amnesia. In Human Memory and Amnesia, L. Cermak (Editor). Lawrence Erlbaum, Hillsdale, New Jersey, 1981, in press.

44. Huppert, F. A and Piercy, M. Dissociation between learning and remembering in organic amnesia. Nature 275, 317-318, 1978.

45. SQurre, L. R. Two forms of human amnesia: an analysis of forgetting. $J$. Neuroscience, 1981 , in press.

46. Huppert, F. A. and PIERCY, M. Normal and Abnormal forgetting in organic amnesia: effect of locus of lesion. Cortex 15, 385-390, 1979. 
47. McGaugh, J. L. and Her7, M. J. (Editors). Memory Consolidation. Albion, San Francisco, 1972.

48. Russell, W. R. and Nathan, P. W. Traumatic amnesia, Brain 69, 280-300, 1946.

49. Wickelgren, W. A. Chunking and consolidation: a theoretical synthesis of semantic networks, configuring in conditioning, S-R versus cognitive learning, normal forgetting, the amnesic syndrome and the hippocampal arousal system. Psychological Review 86, 44-60, 1979.

50. Warrington, E. K. and Weiskrantz, L. The amnesic syndrome: consolidation or retrieval? Nature 228, $628 \cdots 630,1970$.

51. Inglis, J. Shock, surgery and cerebral asymmetry. Br. J. Psychiat. 117, 143-148, 1970.

52. Drachman, D. A. and Adamis, R. D. Acute herpes simplex and inclusion body encephalitis. Archs Neurol. 7, $45-63,1962$.

53. Brierley, J. B. Neuropathology of amnesic states, In Amnesia. C. W. M. WhitTy and O. L. ZanGWit.L (Editors). Butterwolths, London, 1977.

54. Albert, M. S., Butters, N. and Levin, J. Memory for remote events in chronic alcoholies and alcoholic Korsakoff patients. In Alcohol Intoxication and Withdrawal. H. BEgleIter and B. KISSEN (Editors). Plenum Press, New York, 1979b

55. Mair, W. G. P., Warrington, E. K. and Weiskrantz, L. Memory disorder in Korsakoff's psychosis. Brain 102, 749-783, 1979.

56. Soutirf, I. R., Wft7.fi, C. D. and Siater, P. C. Anterograde amnesia following ECT: an analysis of the beneficial effects of partial information. Neuropsychologia 16, 339 348, 1978.

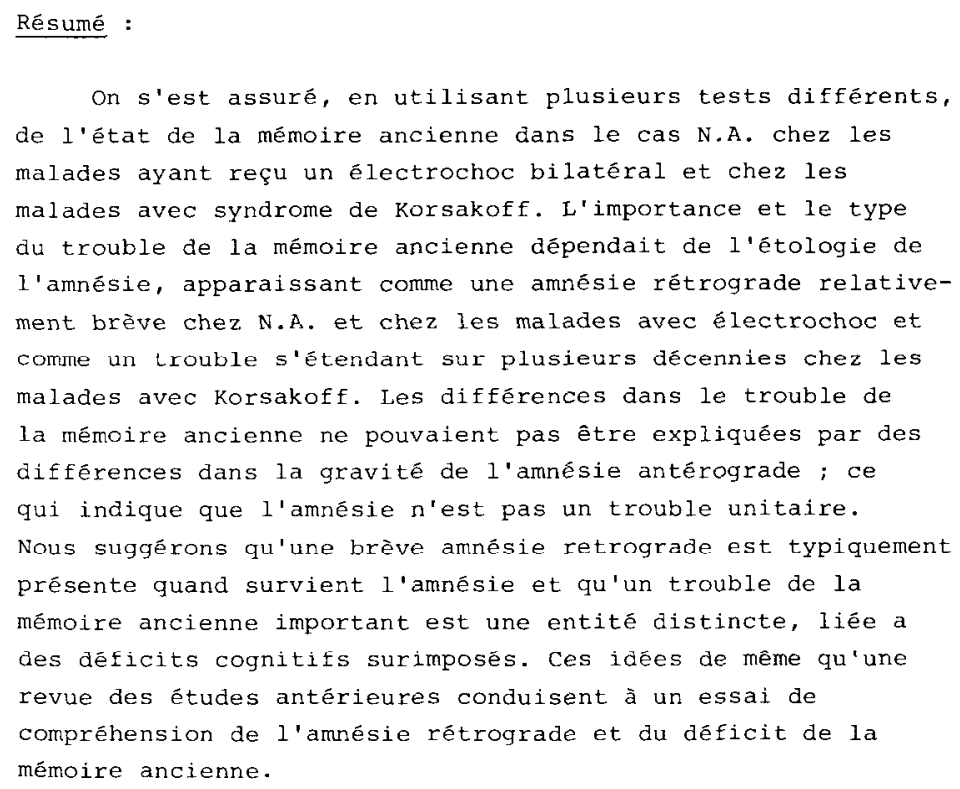


Zusammenfassung:

Das Altgedächtnis wurde bei dem Fall N. A., bei Patienten. die bilateral Elektrokrampfbehandlung erhielten und bei Patienten mit Korsakoff-Syndrom mit verschiedenen Tests untersucht. Das Ausmaß und das Muster der.Gedächtnisstörung hing von der Ätiologie der Amnesie ab, es war eine relativ kurze retrograde Amnesie für N. A. und für Patienten die Elektrokrampfbehandlung erhielten und eine sehr ausgedehnte Beeinträchtigung für viele Jahrzehnte bei Patienten mit Korsakoff-Syndrom. Unterschiede in der Beeinträchtigung des Altgedächtnisses konnten nicht durch Unterschiede in der Schwere der anterograden Amnesie erklärt werden. Daraus ergibt sich, daß die Amnesie keine einheitliche Störung ist. Wir schlagen vor, daß eine kurze retrograde Amnesie in typischer Weise vorhanden ist, wann immer eine Amnesie auftritt, und daß eine länger dauernde Störung des Altgedächtnisses eine Einheit ist, die zu überlagemden kognitiven Störungen Beziehungen hat. Diese Gedanken und ein Überblick über frühere Untersuchungen führen zu einem Vorschlag für ein umfassendes Verständnis der retrograden Amnesie und der Störung des Altgedächtnisses. 